\title{
Ultrasound biomicroscopy as a diagnostic tool in infants with primary congenital glaucoma
}

This article was published in the following Dove Press journal:

Clinical Ophthalmology

5 September 2014

Number of times this article has been viewed

\author{
Tarek R Hussein \\ Said M Shalaby \\ Molham A Elbakary \\ Rabab M Elseht \\ Rania E Gad \\ Faculty of Medicine, Tanta \\ University, Tanta, Egypt
}

Correspondence: Molham A Elbakary Faculty of Medicine, Tanta University, Postal No 31527, Tanta, Egypt

Tel +20 408282205

Fax +20403407734

Email melbakary75@yahoo.com
Purpose: Studying the role of ultrasound biomicroscopy (UBM) in detection of anterior segment changes in infants with primary congenital glaucoma (PCG).

Methods: Cross-sectional study that included 25 eyes of 15 patients suffering from PCG and a control group of 15 eyes of ten age- and sex-matched participants. Diagnosis of PCG was based on clinical data (intraocular pressure, corneal diameter, fundus examination and amplitude-modulation scan measurement of axial length). UBM examination was done for all participants for measurement of central corneal thickness, anterior chamber depth, lens thickness, iris thickness (measured $2 \mathrm{~mm}$ from the iris root and again at the thickest point near the pupil), zonular length, posterior chamber depth, and angle of anterior chamber. Qualitative evaluation was done for abnormal angle membranes, iris insertion level, and ciliary processes position and configuration.

Results: Mean age \pm standard deviation was $10.32 \pm 3.59$ months in the study group and $14.54 \pm 5.9$ months in the control group. The central corneal thickness, anterior chamber depth, zonular length, and angle of anterior chamber were significantly larger in the study group than in the control group, with mean values $700 \pm 190 \mu \mathrm{m}, 3.55 \pm 0.32 \mathrm{~mm}, 1.02 \pm 0.15 \mathrm{~mm}$, and $58.47^{\circ} \pm 5.57^{\circ}$, respectively. The posterior chamber depth had a mean of $0.33 \pm 0.06 \mathrm{~mm}$, which was significantly smaller than that of the control group. In the study group, the mean iris thickness $2 \mathrm{~mm}$ from the iris root was $0.32 \pm 0.04 \mathrm{~mm}$, the mean iris thickness at the thickest point near the pupil was $0.38 \pm 0.08 \mathrm{~mm}$, and the mean lens thickness was $3.32 \pm 0.18 \mathrm{~mm}$. These three parameters were smaller than the control group but the difference was insignificant. Loss of normal iris configuration was detected in all eyes of the study group. Anterior iris insertion was detected in $56 \%$ of the eyes in the study group, and abnormal angle membrane was found in $12 \%$.

Conclusion: UBM is a useful tool for detection of anterior segment changes in PCG, which is helpful especially in cases with opaque cornea or cases with borderline clinical findings.

Keywords: UBM, primary congenital glaucoma, buphthalmos

\section{Introduction}

Pediatric glaucoma includes a wide variety of conditions which result in elevated intraocular pressure (IOP) and optic nerve damage. It is a rare but serious cause of blindness around the world and represents a global problem that poses a diagnostic and therapeutic challenge to the ophthalmologist. Primary congenital glaucoma (PCG), the most common primary childhood glaucoma, is believed to be caused by dysplasia of the anterior chamber angle, and it is generally bilateral. ${ }^{1-6}$

The pathogenesis of glaucoma in childhood and the responses of the child's eye to this disorder are often very different from those in older individuals. Exposure to high IOP while the ocular coats are not fully mature in children leads to secondary changes like increased axial length (AL) and associated myopia, iris thinning, and increased corneal diameter. ${ }^{7,8}$ 
Ultrasound biomicroscopy (UBM) is a high-resolution ultrasound technique that allows noninvasive in vivo imaging of structural details of the anterior ocular segment at near light microscopic resolution and provides detailed assessment of anterior segment structures, including those obscured by normal anatomic and pathologic relations (such as corneal edema or iridocorneal abnormalities that may preclude the clinical assessment of underlying structures). Consequently, UBM is useful for assessing the morphology and understanding the pathology of the anterior segment in congenital glaucoma. ${ }^{9,10}$

\section{Patients and methods}

This was a cross-sectional nonrandomized study that included 25 eyes of 15 patients (ten bilateral and five unilateral) diagnosed as PCG in the Pediatric Ophthalmology Unit, Tanta University Eye Hospital, Tanta, Egypt. The study also included an age- and sex-matched control group that consisted of 15 eyes of ten participants (five participants suffering from strabismus with normal clinical findings who were examined under general anesthesia for performing refraction, and the fellow normal eyes of the the five patients with unilateral PCG from the study group). All participants were examined under general anesthesia. Diagnosis of PCG was based on such clinical data as IOP, corneal diameter, disc changes, gonioscopy if possible, and amplitude-modulation scan measurement of axial length (Table 1).

UBM examination (Sonomed Vumax UBM 35 MHz tranducer) was done for all participants for anterior segment biometric quantitative evaluation (Figure 1). This included:

- Central corneal thickness (CCT): measured from the center inner surface of corneal endothelium to outer epithelial surface.

- Anterior chamber depth (ACD): measured from the center of corneal endothelium to the anterior lens capsule.

Table I The mean intraocular pressure, corneal diameter, and axial length in patient and control groups

\begin{tabular}{llllll}
\hline & Group & Mean & SD & $\begin{array}{l}\text { Student's } \\
\text { t-test }\end{array}$ & P-value \\
\hline IOP $(\mathrm{mmHg})$ & Patient & 25.9 & 5.16 & $5.01 \mathrm{I}$ & 0.001 \\
& Control & 14.2 & 3.2 & & \\
$\mathrm{CD}(\mathrm{mm})$ & Patient & 13.12 & 0.63 & 4.137 & 0.001 \\
& Control & 10.9 & 0.60 & & \\
$\mathrm{AL}(\mathrm{mm})$ & Patient & 23.11 & 1.6 & 2.593 & 0.015 \\
& Control & 20.2 & 0.8 & & \\
\hline
\end{tabular}

Abbreviations: $A L$, axial length; $C D$, corneal diameter; IOP, intraocular pressure; $\mathrm{SD}$, standard deviation.
- Lens thickness: measured from anterior to posterior lens capsule.

- Zonular length: measured from the tip of ciliary processes to the lens equator.

- Posterior chamber depth (PCD): measured from the iris pigment epithelium to the first visible zonular fiber at a point just leaving the ciliary process.

- Iris thickness 1 (IT1): measured $2 \mathrm{~mm}$ from the iris root.

- Iris thickness 2 (IT2): measured at the thickest point near the pupil.

- Anterior chamber angle measured in degrees.

- Qualitative evaluation: included detection of abnormal tissues or membranes at the angle of anterior chamber, any abnormalities involving Descemet's membrane or Schwalbe's line, iris insertion level, and ciliary processes position and configuration (Figure 2).

\section{Results}

The study group included 25 eyes of 15 patients with PCG. Five patients $(33.3 \%)$ had unilateral PCG. Ten patients $(66.7 \%)$ were males and five patients $(33.3 \%)$ were females. The control group included 15 eyes of ten participants (ten eyes of five normal participants, and five normal fellow eyes of the five patients with unilateral PCG). Six participants $(60 \%)$ of the control group were males and four participants (40\%) were females, with no significant difference in comparison with the study group ( $P=0.482)$. The age of patients of the study group ranged between 1-24 months with a mean of $10.32 \pm 3.59$ months, while the age in the control group ranged between 2-24 months with a mean of $14.54 \pm 5.9$ months, with no significant differences between groups $(P=0.067)$.

UBM evaluation of both groups revealed that CCT in the study group was significantly larger than in the control group $(P=0.012)$. CCT in the study group ranged between $500-1,390 \mu \mathrm{m}$ with a mean of $700 \pm 190 \mu \mathrm{m}$, while in the control group it ranged between 490-620 $\mu \mathrm{m}$ with a mean of $540 \pm 30 \mu \mathrm{m}$. Similarly, ACD and zonular length in the study group were significantly larger than in the control group $(P=0.001)$. Angle of anterior chamber was significantly wider in the study group ( $P=0.002$ ) (Table 2 ).

PCD was found to be significantly smaller in the study group $(P=0.001)$. Iris thickness (IT1 and IT2) and lens thickness were smaller in the study group, but no statistically significant differences compared with the control group were recorded ( $P=0.394, P=0.105$, and $P=0.206$, respectively) (Table 3 ).

AL is a very valuable tool in diagnosis and follow-up of PCG. The correlations between AL and UBM parameters 

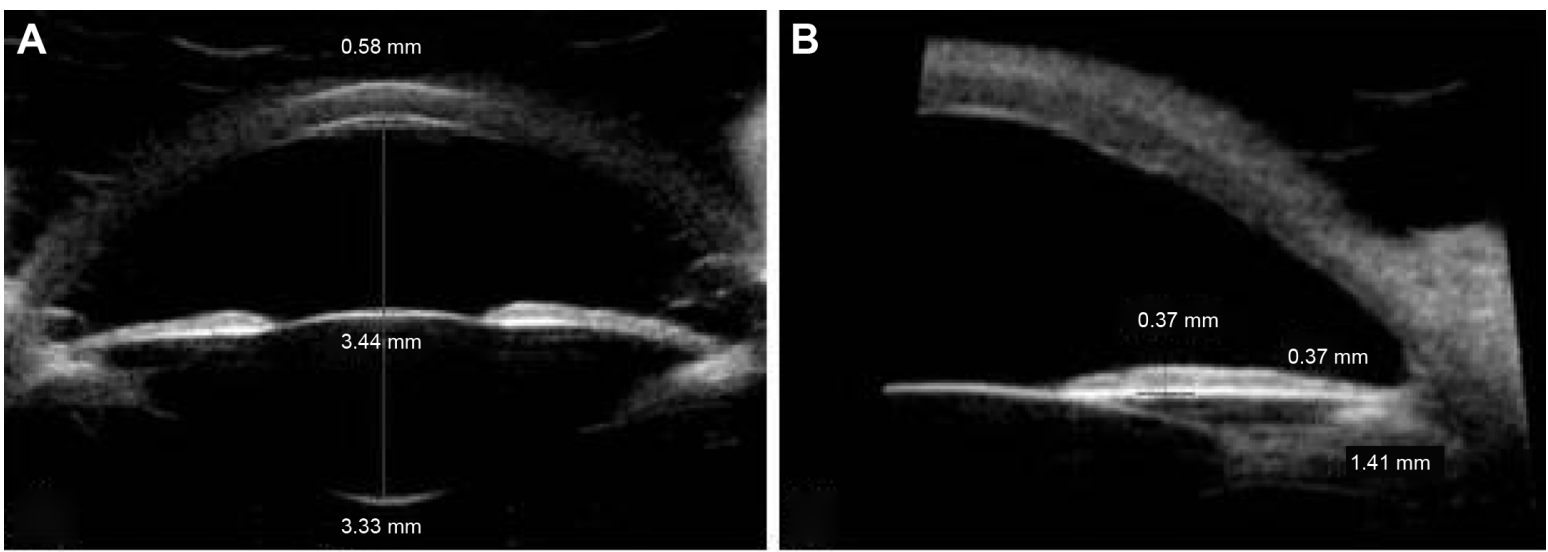

Figure I Different anterior segment measurements in eye with primary congenital glaucoma.

Notes: (A) Central corneal thickness, anterior chamber depth, and lens thickness. (B) Iris thickness 2 (measured at the thickest point near the pupil), posterior chamber depth, and zonular length.
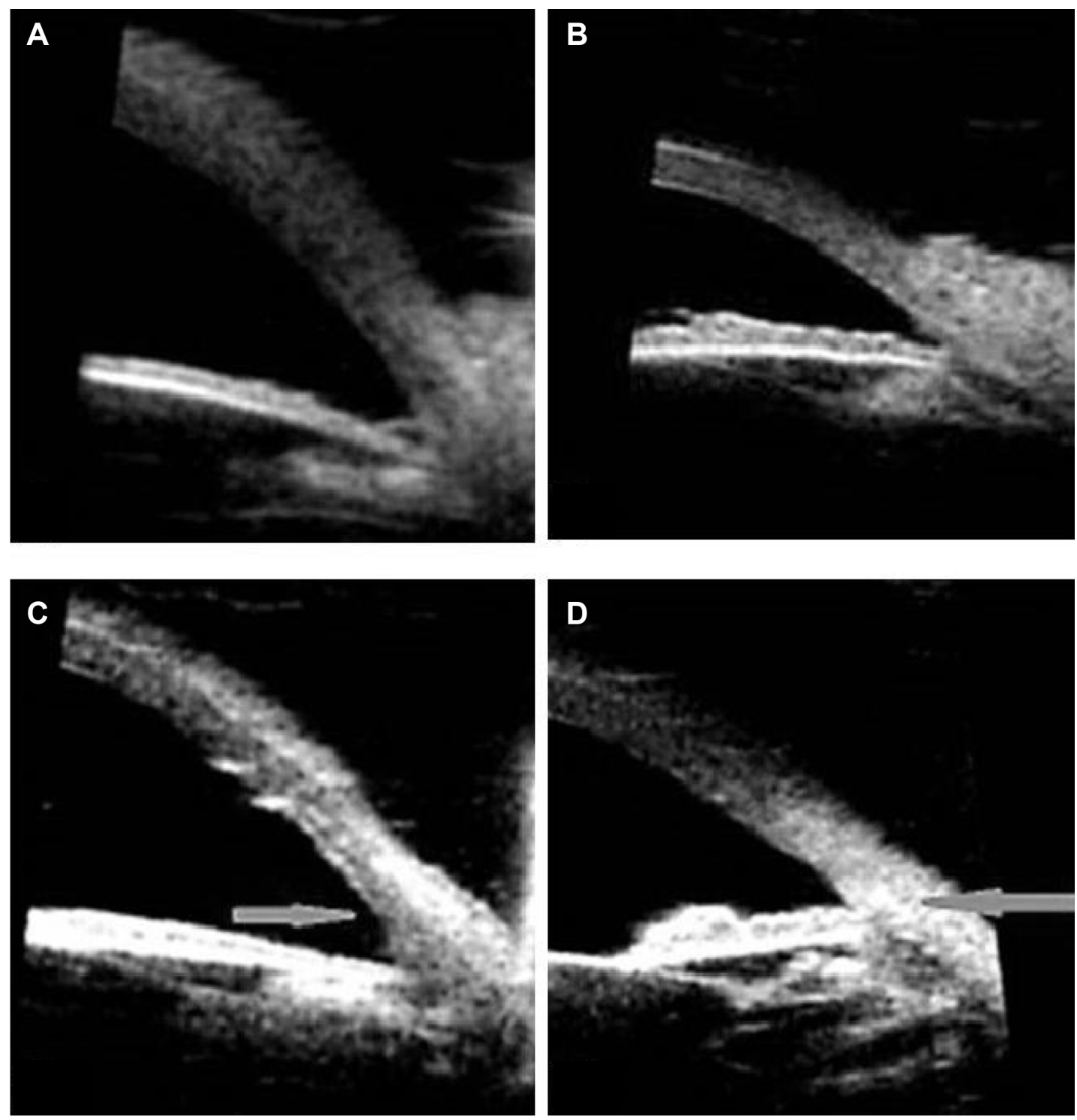

Figure 2 Qualitative anterior segment changes.

Notes: (A) Loss of normal iris configuration with abnormal angle membrane. (B) Preserved iris crypts in an eye of normal control. (C) Glaucomatous eye with normal iris insertion in relation to sclera spur (arrowhead). (D) Glaucomatous eye with anterior iris insertion in relation to sclera spur (arrowhead). 
Table 2 The mean central corneal thickness, anterior chamber depth, zonular length, and angle measurement in patient and control groups

\begin{tabular}{llllll}
\hline & Group & Mean & SD & $\begin{array}{l}\text { Student's } \\
\text { t-test }\end{array}$ & P-value \\
\hline CCT $(\mu \mathrm{m})$ & Patient & 700 & 190 & 2.639 & 0.012 \\
& Control & 540 & 30 & & \\
ACD $(\mathrm{mm})$ & Patient & 3.55 & 0.32 & 6.372 & 0.001 \\
& Control & 2.69 & 0.45 & & \\
Zonular & Patient & 1.02 & 0.15 & 4.318 & 0.001 \\
length (mm) & Control & 0.77 & 0.16 & & \\
Angle & Patient & 58.47 & 5.57 & 3.422 & 0.002 \\
(degrees) & Control & 51.04 & 6.90 & & \\
\hline
\end{tabular}

Abbreviations: ACD, anterior chamber depth; CCT, central corneal thickness; $\mathrm{SD}$, standard deviation

were studied. IT1 and IT2 were found negatively correlated with $\operatorname{AL}(P=0.001$ and $P=0.040$, respectively). A negative correlation was also found between PCD and AL $(P=0.037)$. No correlations were found between other UBM parameters and AL.

Correlations between IOP and corneal diameter (as indicators of severity of PCG) and UBM parameters in the study group were investigated. No significant correlation was found between UBM parameters and IOP, while IT1 was negatively correlated and angle of anterior chamber was positively correlated with corneal diameter $(P=0.037$ and $P=0.027$, respectively). No significant correlation was found between age and any of the UBM parameters in either the study group or the control group.

Qualitatively, different degrees of loss of normal iris configuration with absence of iris crypts were detected in all eyes in the study group. Anterior iris insertion was found in 14 eyes (56\%), while normal iris insertion level was detected in eleven eyes (44\%). Ciliary processes were found to be long and slender, and in eight eyes (32\%) they were closely related to the posterior surface of the iris with very shallow

Table 3 The mean posterior chamber depth, iris thickness, and lens thickness in patient and control groups

\begin{tabular}{llllll}
\hline & Group & Mean & SD & $\begin{array}{l}\text { Student's } \\
\text { t-test }\end{array}$ & P-value \\
\hline PCD $(\mu \mathrm{m})$ & Patient & 330 & 60 & 8.489 & 0.00 I \\
& Control & 560 & 90 & & \\
ITI $(\mu \mathrm{m})$ & Patient & 320 & 40 & 0.863 & 0.394 \\
& Control & 330 & 60 & & \\
IT2 $(\mu \mathrm{m})$ & Patient & 380 & 80 & 1.663 & 0.105 \\
& Control & 440 & 100 & & \\
Lens thickness & Patient & 3.32 & 0.18 & 1.288 & 0.206 \\
$(\mathrm{~mm})$ & Control & 3.44 & 0.39 & & \\
\hline
\end{tabular}

Abbreviations: IT, iris thickness; PCD, posterior chamber depth; SD, standard deviation. or obliterated ciliary sulcus. Abnormal angle membrane was found in three eyes of the study group (12\%), which was not detectable clinically. This may be attributed to unfamiliarity with gonioscopic findings in infants.

\section{Discussion}

UBM systems are suitable for imaging of virtually all anterior segment anatomy and pathology, including the cornea, iridocorneal angle, anterior chamber, iris, lens, retroirideal structures, and ciliary processes. ${ }^{11}$ There are few studies on UBM changes in the anterior segment in eyes with congenital glaucoma. ${ }^{9,12,13}$ Gupta et al ${ }^{13}$ published the UBM characteristics of the anterior segment in PCG. They included only patients older than 5 years who were cooperative for UBM examination. The mean age of their patients was $13.8 \pm 3.2$ years. They found that anterior chamber angle (in degrees), zonular length, and PCD were significantly larger in glaucomatous eyes. On the other hand, lens thickness, iris thickness, and ciliary body thickness were significantly smaller in glaucomatous eyes.

It is well known that eyes with congenital glaucoma are significantly more myopic, and that myopic nonglaucomatous eyes have greater ACD, thinner lenses, and greater axial lengths. ${ }^{14}$ Garner et al ${ }^{15}$ described a thinning of the lens of $0.005 \mathrm{~mm}$ per year in myopic children. Anterior segment changes detected in glaucomatous eyes cannot be attributed to accompanying myopia, as these changes are much more pronounced in eyes with congenital glaucoma. They can be better explained by the progressive stretching of the globe in these eyes. ${ }^{13}$ Results of our study showed that the previously described characteristic glaucomatous changes in anterior segment parameters can be detected at a much younger age (10.32 \pm 3.59 months).

Gupta et $\mathrm{al}^{13}$ studied the correlations between UBM parameters and AL. They found moderate negative correlation between iris thickness and AL. Zonular length in their study correlated positively with AL. They found no correlations between AL and anterior chamber angle, ciliary body thickness, or PCD. In this series, negative correlation was found between each of IT1, IT2, PCD, and AL.

CCT in glaucomatous eyes was found to be significantly larger in the study group than the control group, and no correlation was found between $\mathrm{CCT}$ and corneal diameter. CCT has a known effect on IOP measurement with applanation tonometry. IOP is underestimated in structurally thinner corneas, whereas it is overestimated in structurally thicker corneas. ${ }^{16}$ In addition to the known effect of CCT on applanation tonometry, Tong and associates ${ }^{17}$ demonstrated that 
changes in CCT were associated with a greater difference in measured IOP in children than in adults. Lopes et a ${ }^{18}$ stated that CCT could have a clinically significant effect on IOP measurement in more than half of the patients with pediatric glaucoma and suggested that pachymetry results should be considered in the management of such cases. Published data are ambiguous regarding CCT in PCG cases, with both thicker and thinner corneas being reported.

Some studies reported a significantly thinner cornea in PCG patients. ${ }^{18-20}$ Wygnanski-Jaffe and Barequet ${ }^{21}$ reported nine congenital glaucoma cases with thinner CCT in the eye with the more severe glaucomatous damage in bilateral cases or in the glaucomatous eye compared with the normal fellow eye in unilateral glaucoma cases. These findings were explained by the corneal stretching and/or scarring.

On the other hand, other studies reported significantly thicker CCT in patients with PCG. ${ }^{8,22,23}$ Corneal thickening in congenital glaucoma could be an inherent component of the pathophysiology and related to racial and genetic background. Alternately, the thicker cornea could be due to the presence of subclinical corneal edema as a result of endothelial dysfunction and long-lasting IOP elevation. ${ }^{23}$ Oberacher-Velten et $\mathrm{al}^{22}$ concluded that even apparently clear corneas under high IOP in congenital glaucoma might have subclinical edema. Mastropasqua et $\mathrm{al}^{24}$ used confocal microscopy to study the endothelial layer in two patients with glaucomatous megalocornea. They found markedly decreased cell density, pleomorphism, and focal cellular lesions, which were attributed to corneal distension.

Many investigators used ultrasound pachymetry for evaluation of CCT in PCG patients, while in our study UBM was used. Tam and Rootman ${ }^{25}$ compared measurement of CCT using specular microscopy, ultrasound pachymetry, and UBM. They found both ultrasound pachymetry and UBM produced similar measurements.

Different degrees of loss of normal iris configuration with absence of iris crypts were detected in all eyes with congenital glaucoma. This may be explained on a pathological basis due to lacking of sphincter and dilator muscles, while uveal and neuroepithelial layers are preserved. ${ }^{26}$

Anterior iris insertion was found in $56 \%$ of the eyes in the study group. Zhu et $\mathrm{al}^{27}$ found the sclera spur lateral or posterolateral to the angle apex in $75 \%$. They concluded that the relative positional changes between sclera spur and angle apex indicates that the poor development of sclera spur and the anterior iris insertion are basic pathogenic factors in PCG. An important characteristic feature in congenital glaucoma is the massively elongated ciliary processes.
These elongated processes might be drawn into the trabeculectomy cleft, accounting for the high incidence of uveal tissue incarceration. ${ }^{9,12,28,29}$

There are no published data about the use of UBM for follow-up of patients with congenital glaucoma, but it is well established that AL measurement has been reported to be a simple and very valuable tool for follow-up of such patients. ${ }^{8,30}$

In conclusion, eyes with primary congenital glaucoma have characteristic anterior segment features that can be detected by UBM, even in infants 2 years old or younger. These UBM characteristics are helpful in establishing a primary congenital glaucoma diagnosis, especially in patients with opaque cornea or borderline clinical features.

\section{Disclosure}

The authors report no conflicts of interest in this work.

\section{References}

1. Morales J, Al Shahwan S, Al Odhayb S, Al Jadaan I, Edward DP. Current surgical options for the management of pediatric glaucoma. J Ophthalmol. 2013;2013:763735.

2. Fung DS, Roensch MA, Kooner KS, Cavanagh HD, Whitson JT. Epidemiology and characteristics of childhood glaucoma: results from the Dallas Glaucoma Registry. Clin Ophthalmol. 2013;7:1739-1746.

3. Mandal AK, Chakrabarti D. Update on congenital glaucoma. Indian J Ophthalmol. 2011;59(Suppl):S148-S157.

4. Papadopoulos M, Cable N, Rahi J, Khaw PT; BIG Eye Study Investigators. The British Infantile and Childhood Glaucoma (BIG) Eye Study. Invest Ophthalmol Vis Sci. 2007;48(9):4100-4106.

5. Taylor RH, Ainsworth JR, Evans AR, Levin AV. The epidemiology of pediatric glaucoma: the Toronto experience. J AAPOS. 1999; 3(5):308-315.

6. deLuise VP, Anderson DR. Primary infantile glaucoma (congenital glaucoma). Surv Ophthalmol. 1983;28(1):1-19.

7. Freedman SF, Walton DS. Diagnosis and treatment of glaucoma in children. In: Chandler PA, Grant WM, Epstein DL, Allingham RR, Schuman JS, editors. Chandler and Grant's Glaucoma. 4th ed. Baltimore, MD: Lippincott Williams \& Wilkins; 1996:586-608.

8. Sampaolesi R, Caruso R. Ocular echometry in the diagnosis of congenital glaucoma. Arch Ophthalmol. 1982;100(4):574-577.

9. Azuara-Blanco A, Spaeth GL, Araujo SV, et al. Ultrasound biomicroscopy in infantile glaucoma. Ophthalmology. 1997;104(7):1116-1119.

10. Dada T, Gadia R, Sharma A, et al. Ultrasound biomicroscopy in glaucoma. Surv Ophthalmol. 2011;56(5):433-450.

11. Silverman RH. High-resolution ultrasound imaging of the eye - a review. Clin Experiment Ophthalmol. 2009;37(1):54-67.

12. Dietlein TS, Engels BF, Jacobi PC, Krieglstein GK. Ultrasound biomicroscopic patterns after glaucoma surgery in congenital glaucoma. Ophthalmology. 2000;107(6):1200-1205.

13. Gupta V, Jha R, Srinivasan G, Dada T, Sihota R. Ultrasound biomicroscopic characteristics of the anterior segment in primary congenital glaucoma. J AAPOS. 2007;11(6):546-550.

14. Nomura H, Ando F, Niino N, Shimokata H, Miyake Y. The relationship of intraocular pressure and refractive error adjusting for age and central corneal thickness. Ophthalmic Physiol Opt. 2004;24(1): $41-45$.

15. Garner LF, Stewart AW, Owens H, Kinnear RF, Frith MJ. The Nepal Longitudinal Study: biometric characteristics of developing eyes. Optom Vis Sci. 2006;83(5):274-280. 
16. Whitacre MM, Stein RA, Hassanein K. The effect of corneal thickness on applanation tonometry. Am J Ophthalmol. 1993;115(5):592-596.

17. Tong L, Saw SM, Siak JK, Gazzard G, Tan D. Corneal thickness determination and correlates in Singaporean schoolchildren. Invest Ophthalmol Vis Sci. 2004;45(11):4004-4009.

18. Lopes JE, Wilson RR, Alvim HS, et al. Central corneal thickness in pediatric glaucoma. J Pediatr Ophthalmol Strabismus. 2007;44(2):112-117.

19. Henriques MJ, Vessani RM, Reis FA, de Almeida GV, Betinjane AJ, Susanna R. Corneal thickness in congenital glaucoma. J Glaucoma. 2004;13(3):185-188.

20. Tai TY, Mills MD, Beck AD, et al. Central corneal thickness and corneal diameter in patients with childhood glaucoma. $J$ Glaucoma. 2006;15(6):524-528.

21. Wygnanski-Jaffe T, Barequet IS. Central corneal thickness in congenital glaucoma. Cornea. 2006;25(8):923-925.

22. Oberacher-Velten I, Prasser C, Lorenz B. Evolution of central corneal thickness in children with congenital glaucoma requiring glaucoma surgery. Graefes Arch Clin Exp Ophthalmol. 2008;246(3):397-403.

23. Amini H, Fakhraie G, Abolmaali S, Amini N, Daneshvar R. Central corneal thickness in Iranian congenital glaucoma patients. Middle East Afr J Ophthalmol. 2012;19(2):194-198.
24. Mastropasqua L, Carpineto P, Ciancaglini M, Nubile M, Doronzo E. In vivo confocal microscopy in primary congenital glaucoma with megalocornea. J Glaucoma. 2002;11(2):83-89.

25. Tam ES, Rootman DS. Comparison of central corneal thickness measurements by specular microscopy, ultrasound pachymetry, and ultrasound biomicroscopy. J Cataract Refract Surg. 2003;29(6):1179-1184.

26. Yanoff M, Fine BS. Ocular Pathology. 4th ed. St Louis, MO: MosbyYear Book; 1996:625-667.

27. Zhu X, Li Z, Lin D, et al. [A study of anterior segment structures in primary infantile glaucoma eyes by ultrasound biomicroscopy]. Zhonghua Yan Ke Za Zhi. 1999;35(4):300-304. Chinese.

28. Burke JP, Bowell R. Primary trabeculectomy in congenital glaucoma. Br J Ophthalmol. 1989;73(3):186-190.

29. Lee AJ, Saw SM, Gazzard G, Cheng A, Tan DT. Intraocular pressure associations with refractive error and axial length in children. Br J Ophthalmol. 2004;88(1):5-7.

30. Tarkkanen A, Uusitalo R, Mianowicz J. Ultrasonographic biometry in congenital glaucoma. Acta Ophthalmol (Copenh). 1983;61(4):618-623.
Clinical Ophthalmology

\section{Publish your work in this journal}

Clinical Ophthalmology is an international, peer-reviewed journal covering all subspecialties within ophthalmology. Key topics include: Optometry; Visual science; Pharmacology and drug therapy in eye diseases; Basic Sciences; Primary and Secondary eye care; Patient Safety and Quality of Care Improvements. This journal is indexed on

\section{Dovepress}

PubMed Central and CAS, and is the official journal of The Society of Clinical Ophthalmology (SCO). The manuscript management system is completely online and includes a very quick and fair peer-review system, which is all easy to use. Visit http://www.dovepress.com/ testimonials.php to read real quotes from published authors. 